\title{
Influence of hyperglyceamia on some haemorheological markers in diabetic Nigerians
}

\author{
LA Olatunji ${ }^{\mathrm{a}}$, AO Soladoye $\mathrm{a}^{\mathrm{a}}$, ADA Ighoroje ${ }^{\mathrm{b}}$ and AO Attah ${ }^{\mathrm{a}}$
}

\begin{abstract}
The altered rheological properties of the blood have been shown to precede clinically detectable diabetic vasculopathy. This study seeks to investigate whether hypoglycaemic treatment would have any impact on some haemorheological markers: haematocrit (Hct), total plasma protein (TPP) and relative plasma viscosity (RPV). We studied fifty normotensive diabetic patients that were on insulin, metformin or glibenclamide treatment and 25 non-diabetic subjects matched by age, sex and body mass index (BMI). Results showed that age, BMI, haematocrit, systolic blood pressure (SBP) and diastolic blood pressure (DBP) were similar among all groups. Fasting blood sugar $(\mathrm{FBS})$ which was significantly higher $(\mathrm{p}<0.05)$ in the three groups of diabetic patients when compared to that of the non-diabetic control group. The mean TPP and RPV were significantly elevated ( $\mathrm{p}<0.05$ and $\mathrm{p}<0.01$ respectively) in all the diabetic groups than that observed in non-diabetic control group. In diabetic patients, FBS significantly correlated positively with RPV in either sex while weak positive correlation was found between FBS and RPV in non-diabetics. These results have shown that hyperglycaemia is associated with elevated plasma viscosity and plasma protein levels in diabetic patients. This finding suggests that treatment with insulin, metformin or glibenclamide does not impact beneficial effects on plasma rheology. In addition, the results imply that hyperglycaemia mediates hyperviscous plasma that may exert risk factor for the initiation and/or progression of diabetic vasculopathy. Hence, it may be necessary to use rheomodulators in the management of diabetes mellitus.
\end{abstract}

\section{INTRODUCTION}

Cardiovascular morbidity and mortality represent a main challenge in diabetic patients $^{1,2}$. Aggressive blood pressure control

KEYWORDS: Diabetes mellitus, hyperglycaemia,

hypoglycaemic drugs, plasma viscositytry.

${ }^{a}$ Department of Physiology and Biochemistry, College of Medicine, University of Ilorin, P.M.B. 1515, Ilorin, Nigeria.

${ }^{b}$ Department of ${ }^{1}$ Physiology, College of Medical Sciences, University of Benin, P.M.B. 1156, Benin City, Nigeria.

Correspondence: L.A. Olatunji, Department of Physiology and Biochemistry, College of Medicine, University of Ilorin, P.M.B. 1515, Ilorin, Nigeria. E-mail: tunjilaw04@yahoo.com (Tel.: +234-803-575-5360). and lipid lowering have been shown to reduce stroke and myocardial infarction in patients with diabetes mellitus while cardiovascular mortality remains excessive in them ${ }^{1}$. Interest in the role of haemorheological indices in the aetiology, management, prognosis and complications of diabetes mellitus has increased. Reports in Caucasians have shown altered rheological properties of the blood of patients with diabetes such as increase in plasma viscosity ${ }^{2,4}$, plasma protein concentrations ${ }^{2,5}$, whole blood 
viscosity $^{2,4}$ and haematocrit ${ }^{5,6}$. These alterations in haemorheological indices could explain the increase in hyperviscosity state usually associated with increased risk of cardiovascular, cerebrovascular and retinal venous occlusion morbidity ${ }^{3,7,8}$ more so, that plasma viscosity and haematocrit have been found to be increased in diabetic retinopathy ${ }^{9}$ and glaucoma ${ }^{10}$ as well as in subjects with blurred vision ${ }^{11}$.

Africans are particularly prone to the development of cardiovascular disease ${ }^{12}$. Studies on haemorheological indices in Nigerian diabetics are scarce. $\mathrm{Memeh}^{13}$ reported increased fibrinogen levels and blood viscosity in hypertensive diabetic Nigerians. The objective of the present study therefore is to determine alterations in some haemorheological markers after prolonged hypoglycaemic treatment in patients with diabetic mellitus. We also evaluated the relationship between fasting blood sugar and haemorheological markers as well as to body mass index (BMI). This was done in order to test the hypothesis that cardiovascular complications in diabetics might be mediated by persistent hyperglycaemia.

\section{Materials and Methods}

Patients with uncomplicated diabetes mellitus controlled by insulin, metformin or glibenclamide were recruited from the diabetic clinic of the University of Ilorin Teaching hospital, Ilorin. The non-diabetic patients served as controls and were members of staff of the University of Ilorin. All subjects gave informed consent. Subjects who were smokers, with systolic blood pressure $\equiv 140 \mathrm{mmlag}$ d $\not d a$ ra $s$ b b b b d

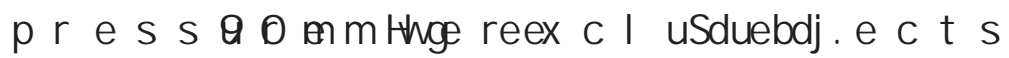
s u f f e $r$ iamgy fostyohset $r e \mathrm{mi} c$ odr $\mathrm{s}$ e a on any other drugs including hormonal c o n t r a c evetr $v$ edsi s a I If or noemd $p$ a $r$ i c i pt ahtsit rugdal g $r$ o uppes $r$ e

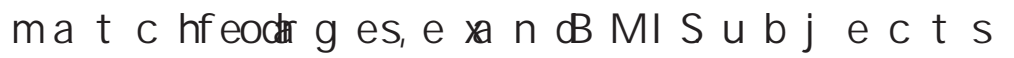
characteristics are shown in Table 1. Measurements of blood pressure, h a e ma t o Imagr i kcearl sf a s t bi Inogo d s u g e r pee $r$ f o r tha $12 \mathrm{~h}-\mathrm{o} v$ ef ransingehets to il $r$ rde s s u r e

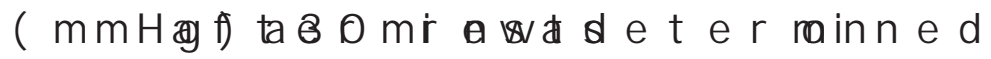
$\mathrm{t}$ hber a $\mathrm{c}$ dn ri tale $s$ iyanugs $\mathrm{c} u$ I no eatt ho or dy. A b o a $0 \mathrm{mb}$ b e n obulso \& o l l e c t e d a $n$ da $n$ to ia gautle d $i t d h r$ yd $i$ esmi $u$ $E D T^{7} A$ All haemorheological parameters were analyzed within four hours of blood collection. The Hct (\%) was analyzed by Hawksley capillary centrifugation at 3000rpm for $10 \mathrm{~min}$ and RPV was assessed by capillary viscometry ${ }^{14}$ at $37^{0} \mathrm{C}^{14}$. Hct and RPV were measured in duplicate and averaged for each sample. TPP (g/l) was determined by micro-biuret method ${ }^{7,14}$. Fasting blood glucose concentrations (mmol/l) were determined by coupled enzymatic colourimetric method.

Statistical analysis: Data were expressed as means \pm SEM (range). Pearson's correlation coefficients were calculated between FBS and Hct, RPV, TPP and BMI in diabetics and non-diabetics. Statistical comparisons among groups were done using the student's t-test. Statistical significance was accepted when $\mathrm{p}<0.05$. 
viscosity $^{2,4}$ and haematocrit ${ }^{5,6}$. These alterations in haemorheological indices could explain the increase in hyperviscosity state usually associated with increased risk of cardiovascular, cerebrovascular and retinal venous occlusion morbidity ${ }^{3,7,8}$ more so, that plasma viscosity and haematocrit have been found to be increased in diabetic retinopathy ${ }^{9}$ and glaucoma ${ }^{10}$ as well as in subjects with blurred vision ${ }^{11}$.

Africans are particularly prone to the development of cardiovascular disease ${ }^{12}$. Studies on haemorheological indices in Nigerian diabetics are scarce. $\mathrm{Memeh}^{13}$ reported increased fibrinogen levels and blood viscosity in hypertensive diabetic Nigerians. The objective of the present study therefore is to determine alterations in some haemorheological markers after prolonged hypoglycaemic treatment in patients with diabetic mellitus. We also evaluated the relationship between fasting blood sugar and haemorheological markers as well as to body mass index (BMI). This was done in order to test the hypothesis that cardiovascular complications in diabetics might be mediated by persistent hyperglycaemia.

\section{Materials and Methods}

Patients with uncomplicated diabetes mellitus controlled by insulin, metformin or glibenclamide were recruited from the diabetic clinic of the University of Ilorin Teaching hospital, Ilorin. The non-diabetic patients served as controls and were members of staff of the University of Ilorin. All subjects gave informed consent. Subjects who were smokers, with systolic blood pressure $\equiv 140 \mathrm{mmlag}$ d $\not d a$ ra $s$ b b b b d

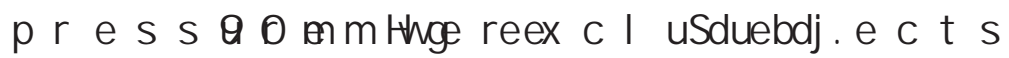
s u f f e $r$ iamgy fostyohset $r e \mathrm{mi} c$ odr $\mathrm{s}$ e a on any other drugs including hormonal c o n t r a c evetr $v$ edsi s a I If or noemd $p$ a $r$ i c i pt ahtsit rugdal g $r$ o uppes $r$ e

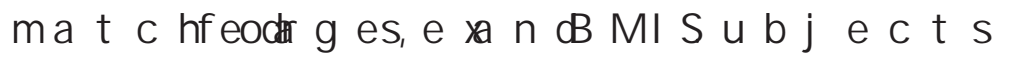
characteristics are shown in Table 1. Measurements of blood pressure, h a e ma t o Imagr i kcearl sf a s t bi Inogo d s u g e r pee $r$ f o r tha $12 \mathrm{~h}-\mathrm{o} v$ ef ransingehets to il $r$ rde s s u r e

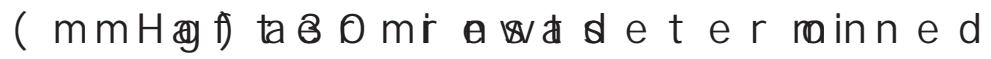
$\mathrm{t}$ hber a $\mathrm{c}$ dn ri tale $s$ iyanugs $\mathrm{c} u$ I no eatt ho or dy. A b o a $0 \mathrm{mb}$ b e n obulso \& o l l e c t e d a $n$ da $n$ to ia gautle d $i t d h r$ yd $i$ esmi $u$ $E D T^{7} A$ All haemorheological parameters were analyzed within four hours of blood collection. The Hct (\%) was analyzed by Hawksley capillary centrifugation at 3000rpm for $10 \mathrm{~min}$ and RPV was assessed by capillary viscometry ${ }^{14}$ at $37^{0} \mathrm{C}^{14}$. Hct and RPV were measured in duplicate and averaged for each sample. TPP (g/l) was determined by micro-biuret method ${ }^{7,14}$. Fasting blood glucose concentrations (mmol/l) were determined by coupled enzymatic colourimetric method.

Statistical analysis: Data were expressed as means \pm SEM (range). Pearson's correlation coefficients were calculated between FBS and Hct, RPV, TPP and BMI in diabetics and non-diabetics. Statistical comparisons among groups were done using the student's t-test. Statistical significance was accepted when $\mathrm{p}<0.05$. 


\section{Results}

Table 1 shows a summary of the characteristics of male and female nondiabetics and male and female diabetics. Results show that male non-diabetics and diabetics had significantly higher $(\mathrm{p}<0.01)$ mean values of Hct than women, while there were no significant sex difference in all other parameters. Non-diabetic subjects were not on any hypoglycaemic drugs. Both male and female diabetics had significantly higher values of FBS, RPV and TPP compared to their non-diabetic counterparts (Table 1).

\section{Table 1}

Characteristics of the non-diabetics and diabetics stratified by sex

Males

\begin{tabular}{|c|c|c|c|c|}
\hline & \multicolumn{2}{|c|}{ Males } & \multicolumn{2}{|c|}{ Female } \\
\hline & $\begin{array}{l}\text { Non-diabetics } \\
\quad(\mathrm{n}=10)\end{array}$ & $\begin{array}{c}\text { Diabetics } \\
(n=20)\end{array}$ & $\begin{array}{l}\text { Non-diabetics } \\
\quad(\mathrm{n}=15)\end{array}$ & $\begin{array}{c}\text { Diabetics } \\
(\mathrm{n}=30)\end{array}$ \\
\hline$\overline{\text { Age (years) }}$ & $\begin{array}{l}46.2 \pm 6.2 \\
(26.0 \quad 68.0)\end{array}$ & $\begin{array}{l}53.9 \pm 3.9^{\mathrm{ns}} \\
(25.076 .0)\end{array}$ & $\begin{array}{l}42.1 \pm 4.0 \\
(29.065 .0)\end{array}$ & $\begin{array}{l}51.1 \pm 3.2^{\text {ns }} \\
(29.075 .0)\end{array}$ \\
\hline $\operatorname{BMI}\left(\mathrm{Kg} / \mathrm{m}^{2}\right)$ & $\begin{array}{l}22.2 \pm 1.5 \\
(19.225 .2)\end{array}$ & $\begin{array}{l}24.9 \pm 1.0^{\text {ns }} \\
(20.035 .6)\end{array}$ & $\begin{array}{l}26.3 \pm 1.9 \\
(19.735 .7)\end{array}$ & $\begin{array}{l}26.9 \pm 1.1^{\mathrm{ns}} \\
(16.438 .7)\end{array}$ \\
\hline $\mathrm{SBP}(\mathrm{mmHg})$ & $\begin{array}{l}122.6 \pm 5.3 \\
(110.0135 .0)\end{array}$ & $\begin{array}{l}123.0 \pm 1.9^{\text {ns }} \\
(110.0135 .0)\end{array}$ & $\begin{array}{l}126.8 \pm 2.3 \\
(100.0 \quad 135.0)\end{array}$ & $\begin{array}{l}20.4 \pm 4.2^{\mathrm{ns}} \\
(100.0135 .0)\end{array}$ \\
\hline $\mathrm{DBP}(\mathrm{mmHg})$ & $\begin{array}{l}75.0 \pm 2.2 \\
(70.085 .0)\end{array}$ & $\begin{array}{l}74.8 \pm 1.7^{\text {ns }} \\
(70.085 .0)\end{array}$ & $\begin{array}{l}75.1 \pm 2.2 \\
(70.085 .0)\end{array}$ & $\begin{array}{l}76.2 \pm 1.3^{\text {ns }} \\
(70.085 .0)\end{array}$ \\
\hline $\operatorname{Hct}(\%)$ & $\begin{array}{l}44.6 \pm 0.6 \\
(39.046 .0)\end{array}$ & $\begin{array}{l}42.6 \pm 1.3^{\mathrm{ns}} \\
(29.049 .0)\end{array}$ & $\begin{array}{c}38.0 \pm 0.7^{+++} \\
(34.043 .0)\end{array}$ & $\begin{array}{l}37.8 \pm 0.8^{++} \\
(26.044 .0)\end{array}$ \\
\hline $\mathrm{TPP}(\mathrm{g} / \mathrm{l})$ & $\begin{array}{l}64.5 \pm 2.6 \\
(54.472 .9)\end{array}$ & $\begin{array}{l}73.6 \pm 2.4^{*} \\
(56.393 .5)\end{array}$ & $\begin{array}{l}67.6 \pm 2.2 \\
(53.085 .5)\end{array}$ & $\begin{array}{l}74.2 \pm 1.8^{*} \\
(56.395 .1)\end{array}$ \\
\hline RPV & $\begin{array}{l}1.41 \pm 0.03 \\
(1.361 .47)\end{array}$ & $\begin{array}{l}1.67 \pm 0.02 * * * \\
(1.521 .83)\end{array}$ & 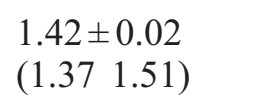 & $\begin{array}{l}1.661 .03^{* * *} \\
(1.501 .84)\end{array}$ \\
\hline $\mathrm{FBS}(\mathrm{mmol} / \mathrm{l})$ & $\begin{array}{l}3.8 \pm 0.5 \\
(3.64 .2)\end{array}$ & $\begin{array}{l}7.0 \pm 0.7^{* *} \\
(3.616 .0)\end{array}$ & $\begin{array}{l}4.0 \pm 0.1 \\
(3.74 .4)\end{array}$ & $\begin{array}{c}6.4 \pm 0.5^{* *} \\
(3.514 .2)\end{array}$ \\
\hline $\begin{array}{l}\text { Current use of } \\
\text { Insulin }\end{array}$ & $n(\%)]:$ & $6(30 \%)$ & - & $10(33 \%)$ \\
\hline Metformin & - & $8(40 \%)$ & - & $12(40 \%)$ \\
\hline Glibenclamide & - & $6(30 \%)$ & - & $8(27 \%)$ \\
\hline
\end{tabular}

Data are given as : means \pm SEM (range); $n$ sample size; BMI body mass index; SBP systolic blood pressure; DBP diastolic blood pressure; Hct Haematorit; TPP total plasma protein; RPV relative plasma viscosity; FBS fasting blood sugar; * $-\mathrm{p}<0.05 ;{ }^{* *} \mathrm{p}<0.01 ; * * * \mathrm{p}<0.001$ versus non-diabetics $++\mathrm{p}$ $<0.01 ;+++\mathrm{p}<0.001$ versus male non-diabetics. 
Table 2 presents haemorheological markers, FBS and BMI in non-diabetics and diabetics on insulin, metformin or glibenclamide treatment. Hct and BMI values were similar in all the four groups. TPP, RPV and FBS were not significantly different among diabetic groups while the mean values of TPP, RPV and FBS obtained from non-diabetics were significantly less than those from the three diabetic groups. In non-diabetic subjects,
FBS did not show any significant correlation with RPV, TPP and BMI. FBS significantly correlated positively with RPV in diabetic males ( $\mathrm{r}=0.85, \mathrm{p}<0.001)$ and females $(\mathrm{r}=$ $0.79, \mathrm{p}<0.001)$. RPV was weakly related to TPP ( $\mathrm{r}=0.45, \mathrm{p}=0.08)$ in both sexes among the diabetic patients. However, FBS levels were weakly related to the haemorheological markers and BMI in non-diabetic subjects.

\section{Table 2}

Summary of haemorheological markers and fasting blood sugar levels in non-diabetics and diabetics on either Insulin, Metformin or a combination of Metformin and Glibenclamide

\begin{tabular}{lllcc}
\hline Variables & Non-diabetics & Insulin & $\begin{array}{c}\text { Diabetics receiving } \\
\text { Metformin }\end{array}$ & Glibenclamide \\
\hline FBS (mmol/l) & $3.8 \pm 0.1$ & $6.4 \pm 1.0^{*}$ & $6.5 \pm 0.8^{* *}$ & $6.2 \pm 0.8^{* *}$ \\
RPV & $1.43 \pm 0.02$ & $1.67 \pm 0.05^{* * *}$ & $1.66 \pm 0.02^{* * *}$ & $1.68 \pm 0.03^{* * *}$ \\
TPP $(\mathrm{g} / \mathrm{l})$ & $66.2 \pm 2.0$ & $74.2 \pm 2.3^{*}$ & $74.5 \pm 2.4^{*}$ & $73.8 \pm 2.1^{*}$ \\
Hct $(\%)$ & $40.8 \pm 0.7$ & $39.8 \pm 2.8^{\mathrm{ns}}$ & $39.2 \pm 1.2^{\mathrm{ns}}$ & $41.3 \pm 1.3^{\mathrm{ns}}$ \\
$\mathrm{n}$ & 25 & 16 & 20 & 14
\end{tabular}

Data given as means \pm ; n, sample size; FBS fasting blood sugar; RPV relative plasma protein; TPP total plasma protein; Hct Haematocrit; ${ }^{*} \mathrm{p}<0.05$; ${ }^{*} \mathrm{p}<0.01$; ${ }^{*}{ }^{*} \mathrm{p}<0.001$ versus nondiabetics.

Table 3:

\section{Correlation coefficients [r] between RPV, FBS and TPP and Hct in male and female diabetics}

$$
\text { RPV FBS TPP Hct }
$$

FBS

\begin{tabular}{lcccl} 
Male & $0.85(\mathrm{p}<0.01)$ & - & $0.15(\mathrm{p}=0.8)$ & $-0.22(\mathrm{p}<0.2)$ \\
\hline Female & $0.79(\mathrm{p}<0.001)$ & - & $0.15(\mathrm{p}=0.8)$ & $-0.22(\mathrm{p}=0.2)$ \\
RPV & & & & \\
Male & - & $0.85(\mathrm{p}<0.001)$ & $0.45(\mathrm{p}=0.08)$ & $0.01(\mathrm{p}=0.5)$ \\
Female & - & $0.79(\mathrm{p}<0.001)$ & $0.45(\mathrm{p}=0.08)$ & $0.01(\mathrm{p}=0.5)$
\end{tabular}

FBS, fasting blood sugar; RPV, relative plasma protein; TPP, total plasma protein; Hct, haematocrit. 


\section{DISCUSSION}

The results of the present study demonstrate significant increases in relative plasma viscosity (RPV) and total plasma protein (TPP) levels in both male and female normotensive diabetic Nigerians, despite glycaemic control threshold achieved by insulin, metformin or glibenclamide (Table 1). The values for fasting blood glucose was similar among the diabetic patients but were significantly higher than the value in nondiabetic subjects. This is in consonance with the findings of previous studies ${ }^{2,4,15,16}$. There were no significant differences in haemorheological markers among the three diabetic groups. The present study extends the findings of previous studies in nondiabetic and diabetic patients with a wider age range (25 76 years), matched for age, sex, body mass index and blood pressure were studied. We also examined the associations between haemorheological markers, body mass index and fasting blood glucose levels and the extent to which hyperglycaemia might contribute to the relationships in either sex.

The contribution of blood glucose to plasma viscosity has been uncertain, as earlier studies did not determine other main markers of plasma viscosity such as plasma protein levels. This study shows that hyperglycaemia contribute strongly, possibly, independently of other factors, to plasma hyperviscosity in diabetic patients. There was weak correlation between blood glucose and plasma viscosity in non-diabetic patients while the association between plasma viscosity and glucose levels was strongly positive in either sex. However, there was a weak positive correlation between relative plasma viscosity and total plasma protein levels which does not reach statistical significant level $(r=0.45, p>0.05)$ in both sexes. The weak relationship between relative plasma viscosity and total plasma protein levels also supports the contention that persistent hyperglycaemia significantly accounts for elevated plasma viscosity in these patients. This finding is in the same line of thought with a previous study in diabetic animals in which there was a significant univariate inverse correlations between cerebral blood flow and hyperglycaemia induced by intraperitonial glucose injection ${ }^{17}$ and in community-based studies which found that diabetic mellitus was independently associated with plasma viscosity, though blood glucose levels were not quantified ${ }^{5,18}$.This study confirms earlier observations that haematocrit is significantly higher in men compared to women ${ }^{7}$ and this may explain the higher risk of cardiovascular disease in men because it has been shown that haematocrit is positively related to incident cardiovascular disease ${ }^{7,8}$. The higher haematocrit values in men with or without diabetes mellitus than in their women counterpart could indicate higher whole blood viscosity because whole blood viscosity is mainly determined by the haematocrit $^{8}$. As a result of this, sex difference in haematocrit appears to be secondary to increase in plasma volume due to hormonal fluid retention in women ${ }^{7}$. This study shows an insignificant decrease in haematocrit in patients with diabetics. Several independent studies have reported variable changes in the haematocrit values of diabetic population ${ }^{2-6,16,17}$.A weak negative correlation was found between blood glucose levels and haematocrit in either sex in the present study (Table 3), suggesting that persistent hyperglycaemia is likely to cause an adaptive response in order to minimize the impact of elevated plasma viscosity and total plasma protein in circulation.

The associations of plasma viscosity and blood glucose with body mass index in the present study were comparable to previous reports $^{5,7}$. We observed insignificant 
relationship between plasma viscosity or fasting blood glucose with body mass index. This finding suggests that the increases in plasma viscosity and total protein associated with hyperglycaemia in diabetic Nigerians is not obesity-induced. Failure of insulin, metformin or glibenclamide treatment to normalize plasma viscosity is consistent with previous studies in caucasians ${ }^{19,20}$. These workers reported that high insulin levels were responsible for hyperviscous plasma in the diabetics, possibly due to its anabolic effect. Taken together, the results of this study have demonstrated that hyperglycaemia strongly contribute to elevated plasma viscosity. The hyperviscosity induced by hyperglycaemia might promote diabetic microvasculopathy $\mathrm{y}^{5,17,18}$, diabetic retinopathy ${ }^{9,10,16}$, impaired vision $^{11}$, and musculo-skeletal pains ${ }^{18}$. We therefore suggest monitoring plasma viscosity in diabetic patients with persistent hyperglycaemia who has any of these symptoms.

In conclusion, this study has shown that plasma viscosity and plasma protein levels were higher in diabetic patients on insulin, metformin, or glibenclamide treatment. In addition, elevated plasma viscosity strongly correlated positively with hyperglycaemia. The results suggest that hyperviscous plasma might reduce perfusion in diabetic microangiopathy and / or retinopathy. Hence, indicating the necessity of very early usage of rheomodulators in diabetic patients.

\section{References}

1. UK Prospective Diabetic Study Group. Tight blood pressure control and risk of macrovascular and microvascular complications in type 2 diabetics: UKPDS 38. Br Med J 1998; 317: 703 713.
2 Young MJ, Bennett JL, Liderth SA, Veves A, Boulton AJ, Douglas JT. Rheological and microvascular parameters in diabetic peripheral neuropathy. Clin Sci (Lond) 1996; 96(3): 183 - 187.

3. Karandikar SS, Bapat RD, Puniyani RR. Haemorheology in diabetic foot. J Postgrad Med 1994; 40(1):21 22.

4 Osterode W, Holler C, Ulberth F. Nutritional antioxidants, red cell membrane fluidity and blood viscosity in type 1 Insulin dependent diabetes mellitus. Diabet Med 1996; 13(12): $1044-1050$.

5 McRury SM, Lennie SE, McCollin P, Balendra R, MacCuish AC, Lowe GDO. Increased red cell aggregation in diabetes mellitus: association with cardiovascular risk factors. Diabetic Medicine.1993; 10:21 - 26.

6 Sandhagen B, Ewald U, Tuvemo T. Haemorheology in insulin dependent diabetes is still normal five years after onset of the disease. Acta Paediatr 1997; 418: 21-23.

7 Woodward M, Rumley A, TunstallPedoe H, Lowe GDO. Associations of blood rheology and interleukin-6 with cardiovascular risk factors and prevalent cardiovascular disease.Br J Haematol 1999; 104: 246-257.

8 Lee AJ. The role of rheological and haemostatic factors in hypertension. J Hum Hypertens 1997; 11: 767-776.

9 Remky A, Arend O, Jung F, Kiesewetter H, Reim M, Wolf S. Haemorheology in patients with branch retinal vein occlusion with and without risk 
factors. Graefes Arch Clin Exp Ophthalmol 1996; 234(Suppl 1):58-62

Hamard P, Hamard H, Dufaux J, Quesnot S. Optic nerve head blood flow using a laser Doppler velocimeter and haemorheology in primary open angle glaucoma and normal pressure glaucoma. $\mathrm{Br} \mathrm{J}$ Ophthalmol 1994; 78(6): 449-453.

11 Brunzell JD. Familial lipoprotein lipase deficiency and other causes of the chylomicronemia syndrome. In: Scriver CR, Beaudet AL, Sly WS, Valle D, Eds. The Metabolic Basis of Inherited Diseases. $6^{\text {th }}$ ed. New York. McGraw Hill: 1989.

12 Nwosu CN, Nwabueze AC, Ikeh VO, Stroke at the prime of life: a study of Nigerian Africans between the ages of 16 and 45 years. East Afr Med J 1992; 69(7): $384-390$.

13 Memeh CU. The relationship between body weight and plasma viscosity in hypertensive diabetic Nigerians. J Hypertens 1990; 8: 711714.

14 Soladoye AO, Olatunji LA, Fawole AA. Haemorheologic consequencies of contraceptive usage among Nigerian women. Biosci Res Comm 1998; 10: 153-156.
Reid HL, Vigilance J, Wright-Pascoe Ra, Choo-Kang E. The influence of persistent hyperglycaemia on hyperfibrinogenaemia and hyperviscosity in diabetes mellitus. West Indian Med J 2000; 49(4): 281284.

16 Bertram B, Wolf S, Kaufhold F, Jung F, Kiesewelter H, Reim M. Rheologic findings in patients with diabetic retinopathy. Fortschr Ophthal 1991; 88(4): 321 - 325.

17 Knudson GM, Tedeschi E, Jakobsen J. The influence of haematocrit and blood glucose on cerebral blood flow in normal and in diabetic rats. Neuroreport 1992; 3(11): 987-989.

Rosenson RS, Shott S, Lu L, Tanguay CC. Hypertriglyceridemia and factors associated with plasma viscocity. Am J Med 2001; 110: 488- 492

19 Fisher Bm, Quin JD, Rumley A, Lennie, Small M, MacCuish Ac, Lowe GAO. Efffects of acute insulin - induced hypoglycaemia on haemostasis, fibrinolysis and haemorheology in insulin dependent diabetic patients and control subjects. Clin Sci (Lond) 1991; 80(5): 525-531

Jansen M, Rillaerts E, De Leeuw I. Effects of Metformin on rheology, lipid parameters and insulin resistance in insulin dependent diabetic patients (IDDM). Biomed Pharmacother 1991; 45(8): 363367. 